\title{
"SITUATION OF URGENCY" AS AN EVALUATIVE CATEGORY IN THE LAW AND PRACTICE OF CRIMINAL JUSTICE
}

\author{
Nina S. Manova \\ Saratov State Academy of Law, Saratov, Russian Federation
}

\begin{abstract}
Introduction: the effectiveness of crime investigation is largely determined by the ability of the criminal procedure legislation to clearly regulate the procedure of criminal proceedings. However, the legislator for a number of reasons is forced to resort to the use of such a method of legal technique as the inclusion in the text of the criminal procedure norms the evaluative categories and terms, the uncertainty of which forces the law enforcement officer to interpret their content at his discretion, based on the level of his legal awareness. In a number of cases, this leads to unjustified restrictions on the rights and freedoms of participants in the criminal proceedings. In this regard, the paper aims to analyze the essence of one of such evaluative concepts used in Art.165 of the Code of Criminal Procedure - "situation of urgency", to study the mistakes made by the law enforcement practice when operating with this concept, and to identify the opportunities to prevent unreasonable restrictions on the rights and freedoms of participants in the process when conducting investigative actions against them. Methods: the methodological framework for the study is the general scientific (dialectical, systemic, structural-functional, logical, etc.) and specific scientific (formal legal, comparative law, etc.) research methods. Results: the author's points of view stated in the paper is based on the generalization of knowledge accumulated in the theory of the criminal procedure and practical experience of decision-making on the conduct of investigative actions in situations of urgency. Based on the analysis of the Code of Criminal Procedure, the theoretical and legal opinion of the Constitutional Court of the Russian Federation, the explanations given in the decision of the Plenum of the Supreme Court, and the provisions of the departmental normative legal acts, the author determines the essence of the category "situation of emergency" and makes recommendations for improving the law enforcement. Conclusions: the legality and validity of investigative actions requiring the court decision in a situation of urgency implies the existence of factual grounds for the investigative action, as well as the justification for the existence of the situation of emergency in the decision of the body of investigation, as it allows you to limit the subjectivity in the decision to conduct the investigative action in this situation.
\end{abstract}

Key words: investigative action; judicial procedure for obtaining permission to conduct an investigative action; situation of urgency.

Citation. Manova N.S. "Situation of Urgency" as an Evaluative Category in the Law and Practice of Criminal Justice. Legal Concept, 2019, vol. 18, no. 2, pp. 42-48. (in Russian). DOI: https://doi.org/10.15688/lc.jvolsu.2019.2.6

Дата поступления статьи: 27.02.2019

\section{«СИТУАЦИЯ, НЕ ТЕРПЯЩАЯ ОТЛАГАТЕЛЬСТВА» КАК ОЦЕНОЧНАЯ КАТЕГОРИЯ В ЗАКОНОДАТЕЛЬСТВЕ И ПРАКТИКЕ УГОЛОВНОГО СУДОПРОИЗВОДСТВА}

\author{
Нина Сергеевна Манова \\ Саратовская государственная академия права, г. Саратов, Российская Федерация
}

\footnotetext{
Введение: эффективность деятельности по расследованию преступлений во многом определяется способностью уголовно-процессуального законодательства четко регламентировать порядок уголовного судопроизводства. Однако законодатель по ряду причин вынужден прибегать к использованию такого приема
} 
юридической техники, как включение в текст уголовно-процессуальных норм оценочных категорий и терминов, неопределенность которых вынуждает правоприменителя интерпретировать их содержание по собственному усмотрению, исходя из уровня своего правосознания. В целом ряде случаев это приводит к необоснованному ограничению прав и свобод участников уголовного судопроизводства. В связи с этим в статье была поставлена цель проанализировать сущность одного из таких оценочных понятий, использованного в ст. 165 УПК РФ, - «ситуация, не терпящая отлагательства», изучить ошибки, допускаемые правоприменительной практикой при оперировании данным понятием, и определить возможности для недопущения необоснованных ограничений прав и свобод участников процесса при проведении в их отношении следственных действий. Методологическую основу работы составляют общенаучные (диалектический, системный, структурно-функциональный, логический и др.) и частнонаучные (формально-юридический, сравнительно-правовой и др.) методы исследования. Результаты: изложенная в работе авторская позиция основана на обобщении накопленных в теории уголовного процесса знаний и практического опыта принятия решений о производстве следственных действий в ситуациях, не терпящих отлагательства. На основании анализа норм УПК РФ, теоретико-правовой позиции Конституционного суда РФ, разъяснений, данных в постановлении Пленума Верховного Суда РФ, и положений ведомственных нормативных актов автор определяет сущность категории «ситуация, не терпящая отлагательства» и делает рекомендации по совершенствованию правоприменительной деятельности. Выводы: законность и обоснованность производства следственных действий, требующих судебного решения, в ситуации, не терпящей отлагательства, предполагает наличие фактических оснований для производства следственного действия, а также обоснования наличия ситуации, не терпящей отлагательства в решении органа расследования, так как именно это позволяет ограничить субъективизм при принятии решения о проведении следственного действия в указанной ситуации.

Ключевые слова: следственное действие, судебный порядок получения разрешения на производство следственного действия; ситуация, не терпящая отлагательства.

Цитирование. Манова Н. С. «Ситуация, не терпящая отлагательства» как оценочная категория в законодательстве и практике уголовного судопроизводства // Legal Concept = Правовая парадигма. - 2019. - T. 18, № 2. -C. 42-48. - DOI: https://doi.org/10.15688/lc.jvolsu.2019.2.6

\section{Введение}

Как справедливо отмечено, «использование оценочных понятий и терминов является устоявшимся приемом законодательной техники» [6, с. 2] и действующий УПК РФ в десятках статей содержит такие термины, которые, как правило, не разъясняются законодателем и не интерпретируются им. Неопределенность указанных терминов вынуждает правоприменителя трактовать их содержание по личному усмотрению, вкладывать в них смысл, соответствующий их собственным представлениям. В ряде случаев это приводит к необоснованному ограничению прав и свобод участников уголовного судопроизводства.

\section{Проблемы толкования «ситуации, не терпящей отлагательства» в правоприменительной практике}

Это отчетливо демонстрирует использованный в ч. 5 ст. 165 УПК РФ термин «ситуация, не терпящая отлагательства». В соответствии с данной нормой «в исключительных случаях, когда производство осмотра жилища, обыска и выемки в жилище, личного обыска, а также выемки заложенной или сданной на хранение в ломбард вещи не терпит отлагательства, их производство допускается на основании постановления следователя (дознавателя) без получения судебного решения». Сотрудники органов расследования толкуют наличие такой ситуации весьма произвольно. Так, по данным А.В. Осипова и П.В. Фомичева, более 50 \% следователей и дознавателей считают, что, например, обыск в жилище без судебного решения можно проводить в нерабочее или тем более в ночное время [17, c. $167 ; 13$, с. 124$]$.

Безусловно, что следователь (дознаватель) самостоятелен при производстве следственных действий. Однако, как правильно отмечено, «наиболее важные из таких решений следователя подвергаются контролю непосредственно в момент принятия, поскольку при их незаконности или необоснованности могут произойти существенные, а порой и невосполнимые нарушения прав и свобод участников уголовного судопроизводства. Остальные же процессуальные действия и решения 
органа расследования могут стать предметом контроля уже после их осуществления» $[17$, c. $124 ; 3$, с. 11]. В соответствии с действующим УПК РФ судебное решение является необходимым условием проведения целого ряда следственных действий, наиболее существенно ограничивающих конституционные права и свободы граждан. Вместе с тем, как уже отмечалось, законодатель предоставляет органу расследования право в ситуации, не терпящей отлагательства, провести некоторые из этих следственных действий без получения судебного решения с последующим уведомлением суда о проведенном следственном действии.

Как свидетельствует практика, органы расследования нередко злоупотребляют такой возможностью, произвольно трактуя следственную ситуацию как не терпящую отлагательства. Поэтому в теории уголовного процесса неоднократно предпринимались попытки дать перечень таких случаев, относя к ним ситуации, «грозящие возможностью совершения нового преступления, уничтожения следов преступления, продолжением преступных действий, препятствующие задержанию подозреваемого» [7, с. 27-30; 1, с. 354-358; 16, с. 369$370 ; 4$, с. 238-240]. В.В. Шабарин к таким ситуациям относит те, которые «приводят следователя к убеждению в том, что отложение проведения следственного действия приведет к уничтожению, повреждению, передаче третьим лицам, а равно порче, изменению свойств и качеств, исчезновению объектов, имеющих значение для уголовного дела, изменению местонахождения трупов или разыскиваемых лиц» $[18$, с. 81$]$. Кроме того, к подобным ситуациям относят также случаи, «когда неотложность проведения следственного действия продиктована необходимостью пресечения случайно выявленной преступной деятельности или опасностью утечки информации» $[10$, с. 15].

\section{Сложности \\ законодательной интерпретации ситуаций, не терпящих отлагательства}

Похожим образом определение ситуаций, не терпящих отлагательства, дают и другие авторы $[8$, с. $55 ; 11$, с. 123$]$, предлагая закре- пить в законе их исчерпывающий перечень «в связи с необходимостью ограничения свободы усмотрения со стороны недобросовестных следователей (дознавателей), искусственно создающих подобную ситуацию для того, чтобы не получать предварительного судебного решения на производство следственного действия» [12, с. 127].

Другие ученые для выработки единого подхода к решению вопроса об отнесении конкретной следственной ситуации к числу не терпящих отлагательства предлагают не давать в законе исчерпывающего переченя таких случаев, а указать критерии, которыми могли бы руководствоваться органы расследования, делая вывод о наличии ситуации, не терпящей отлагательства. Так, профессор А.Б. Соловьев к таким критериям относит следующие:

«- ситуация должна возникнуть неожиданно и вытекать из динамики расследования;

- она должна быть обусловлена дефицитом времени для принятия решения, когда нет возможности без ущерба для результативности следственных действий обращаться в суд либо к прокурору;

- когда непроведение либо несвоевременное проведение следственных действий может повлечь тяжкие последствия (продолжение преступной деятельности, утрату или сокрытие важных доказательств и т. д.)» [15, c. 103-104].

Полагаем, что исчерпывающее законодательное определение случаев, которые могут быть отнесены в той или иной следственной ситуации к числу не терпящих отлагательства, лишь создаст на практике дополнительные проблемы, искусственно ограничивая правоприменителя законодательными установками. Оценка ситуации как исключительной, не терпящей отлагательства, должна даваться органом расследования и судом, исходя из конкретных обстоятельств уголовного дела. $\mathrm{B}$ то же время полная свобода усмотрения в данном вопросе создает потенциальную возможность для злоупотребления со стороны органов расследования. Поэтому правильным представляется мнение о целесообразности формулирования определенных рекомендаций на этот счет Пленумом Верховного Суда РФ, который на основе обобщения следственно- 
судебной практики может дать соответствующие разъяснения [5, с. 10].

\section{Разъяснения Пленума Верховного Суда РФ по поводу ситуаций, не терпящих отлагательства}

В настоящее время в постановлении Пленума Верховного Суда РФ от 1 июня 2017 г. № 19 «О практике рассмотрения судами ходатайств о производстве следственных действий, связанных с ограничением конституционных прав граждан (ст. 165 УПК РФ)» приведен достаточно подробный, но открытый перечень ситуаций, не терпящих отлагательства:

«- когда необходимо реализовать меры по предотвращению или пресечению преступления;

- когда промедление с производством следственного действия позволит подозреваемому скрыться;

- когда возникла реальная угроза уничтожения или сокрытия предметов или орудий преступления;

- когда имеются достаточные основания полагать, что лицо, находящееся в помещении или ином месте, в котором производится какое-либо следственное действие, скрывает при себе предметы или документы, могущие иметь значение для уголовного дела» [14].

Близкий к этому перечень ситуаций, не терпящих отлагательства, приведен в ряде ведомственных нормативных актов (приказе Председателя Следственного комитета РФ от 15 января 2011 г. № 2 «Об организации предварительного расследования в Следственном комитете РФ», приказе Генерального прокуратура РФ от 28 декабря 2016 г. № 826 «Об организации прокурорского надзора за процессуальной деятельностью органов предварительного следствия», в которых к числу подобных ситуаций отнесены случаи, «когда необходимо реализовать меры по предотвращению, пресечению преступления, закреплению его следов; когда фактические основания для производства указанных следственных действий появились в ходе осмотра, обыска и выемки в другом месте; если промедление с их производством позволит подозреваемому скрыться; если неотложность их проведения обусловлена обстановкой только что совершенного преступления; если возникла реальная угроза уничтожения или сокрытия искомых объектов; если имеются достаточные основания полагать, что лицо, находящееся в помещении или ином месте, в котором производятся какие-либо следственные действия, скрывает при себе предметы или документы, могущие иметь значение для уголовного дела, если промедление с производством следственного действия негативно повлияет на возмещение причиненного преступлением ущерба» [20, с. 17].

Таким образом, следственная ситуация может быть истолкована как не терпящая отлагательства, если существует реальная угроза утраты следов преступления или иных вещественных доказательств, продолжения преступной деятельности в случае промедления с производством следственного действия.

Если следственное действие, требующее судебного решения, проводится без его получения в ситуации, не терпящей отлагательства, то в решении органа расследования о его производстве помимо указания на основания для производства соответствующего следственного действия должно быть обосновано наличие исключительной ситуации, делающей возможным вторжение в сферу охраняемых Конституцией РФ прав и интересов личности без разрешения суда. То есть решение следователя (дознавателя) о производстве следственного действия должно содержать четкое обоснование его безотлагательности.

Четкую правовую позицию по этому вопросу сформировал Конституционный Суд РФ, отметив, что «суть последующего судебного контроля предполагает проверку соблюдения следователем требований закона как относительно уголовно-процессуальной формы, так и в части, касающейся установления оснований для производства следственного действия, в том числе обосновывающих его безотлагательность» [12].

Практика осуществления судебного контроля за действиями и решения органов предварительного расследования знает единичные случаи признания незаконным производства следственного действия в ситуации, не терпящей отлагательства. Так, Октябрьский районный суд г. Краснодара признал законным производство обыска в жилище К. в случае, 
не терпящем отлагательства, однако в нарушение ст. 7 УПК РФ суд не привел никаких мотивов принятого решения, а лишь переписал данные из постановления следователя о производстве обыска, но свою оценку им не дал. В связи с этим Краснодарский краевой суд в апелляционном порядке отменил решение суда и признал незаконным производство данного следственного действия [2].

\section{Выводы}

Таким образом, законность и обоснованность производства следственных действий, требующих судебного решения, в ситуации, не терпящей отлагательства, предполагает, прежде всего, наличие реальной угрозы утраты следов преступления или иных вещественных доказательств, продолжения преступной деятельности в случае промедления с производством следственного действия. Кроме того, в решении следователя о проведении такого следственного действия должны быть приведены не только фактические основания для его производства, но также дано обоснование наличия ситуации, не терпящей отлагательства. Это является гарантией от субъективизма в принятии решений следователем (дознавателем) о проведении следственных действий, связанных с вторжением в сферу охраняемых Конституцией РФ свобод граждан, когда они проводятся «в расчете на “авось", на возможность случайного получения нужного доказательства» [19 с. 18-19].

\section{СПИСОК ЛИТЕРАТУРЫ}

1. Акимчев, А. А. Проблемы реализации принципа неприкосновенности жилища в уголовном судопроизводстве / А. А. Акимчев // Проблемы теории и практики уголовного процесса: история и современность. - Воронеж : Изд-во Воронеж. гос. ун-та, 2006. - С. 355-359.

2. Апелляционное постановление Краснодарского краевого суда от 15.05.2014 № 22-2471/14 по уголовному делу № 22К-2471/2014 // База судебных решений «Судебные и нормативные акты». - Электрон. текстовые дан. - Режим доступа: http://sudact. ru/regular/doc/ bFyMNfchT3Zd.

3. Бабич, А. В. Процессуальная самостоятельность и независимость следователя как основа его статуса в уголовном судопроизводстве : дис. ... канд. юрид. наук : 12.00.09 / Бабич Андрей Владимирович. - Саратов, 2011. -218 с.

4. Баранова, М. А. Гарантирует ли часть 5 статьи 165 Уголовно-процессуального кодекса Российской Федерации конституционное право на неприкосновенность жилища? / М. А. Баранова // Конституция Российской Федерации и развитие современной государственности (к 10-летию Конституции Российской Федерации) : сб. докл. по материалам междунар. науч.-практ. конф. (г. Саратов, 34 окт. 2009 г.). - Саратов : Изд-во Саратов. гос. академии права, 2009. - С. 238-240.

5. Баранова, М. А. О некоторых проблемах реализации принципа неприкосновенности жилища при производстве следственных действий / М. А. Баранова, Ш. А. Гасанова, Г. Р. Халилова // Актуальные проблемы уголовного процесса и криминалистики : материалы III Междунар. научпракт. конф. (г. Волгоград, 25 мая 2012 г.). - Волгоград : Изд-во ВолГУ, 2012. - С. 6-12.

6. Безруков, С. С. Оценочные понятия и термины в уголовно-процессуальном законодательстве : автореф. дис. ... канд. юрид. наук / Безруков Сергей Сергеевич. - М., 2001. - 24 с.

7. Герасимова, Л. И. Реализация принципа неприкосновенности жилища при производстве следственных действий / Л. И. Герасимова // Адвокат. 2005. - № 1. - С. 50-52.

8. Жук, О. Д. Особенности производства следственных действий по уголовным делам об организации преступного сообщества (ст. 210 УК РФ) / О. Д. Жук // Законодательство и экономика. - 2003. - № 11. - С. 54-60.

9. Григорьева, Н. Н. Защита жилищных прав граждан в судебном порядке / Н. Н. Григорьева // Законность. - 2017. - № 3. - С. 24-26.

10. Колоколов, Н. А. Граница для следователя / Н. А. Колоколов // ЭЖ-ЮРИСТ. - 2008. - № 44. C. 37-38.

11. Никифорова, Х. П. К вопросу о судебном контроле законности и обоснованности производства следственных действий, ограничивающих конституционные права и свободы личности / Х. П. Никифорова // Вестник ОГУ. - 2015. - № 3 (178). - С. 120-125.

12. Определение Конституционного Суда РФ от 10.03.2005 № 70-О «Об отказе в принятии к рассмотрению жалобы гражданки Дементьевой Аиды Борисовны на нарушение ее конституционных прав частью пятой статьи 165 Уголовно-процессуального кодекса Российской Федерации» // С3 РФ. 2005. - № 20. - Ст. 1917.

13. Осипов, А. В. Нормативная модель исключительных случаев, при которых производство следственных действий не терпит отлагательства / А. В. Осипов // Известия АлтГУ. - 2012. - № 2 (74). C. 124-128. 
14. Постановление Пленума Верховного Суда РФ от 01.06.2017 № 19 «О практике рассмотрения судами ходатайств о производстве следственных действий, связанных с ограничением конституционных прав граждан (статья 165 УПК РФ)» // Российская газета. - 2017. - 09 июня.

15. Соловьев, А. Обеспечение обоснованности проведения осмотра жилища, обыска и выемки в жилище в исключительных случаях, не терпящих отлагательства / А. Соловьев // Уголовное право. 2004. - № 4. - С. 103-104.

16. Уголовно-процессуальное право Российской Федерации : учебник / отв. ред. И.Л. Петрухин. 2-е изд., перераб. и доп. - М. : Проспект, 2007. - 688 с.

17. Фомичев, П. В. Процессуальные основания проведения следственных действий в российском уголовном судопроизводстве : дис. ... канд. юрид. наук / Фомичев Петр Викторович. - Саратов, 2016. - 234 с.

18. Шабарин, В. В. Соблюдение принципа неприкосновенности жилища при производстве следственных действий / В. В. Шабарин // Вестник СанктПетербург. ун-та. - 2012. - № 3. - С. 80-82.

19. Шейфер, С. А. Следственные действия. Основания, процессуальный порядок и доказательственное значение / С. А. Шейфер. - Самара : Изд-во Самар. ун-та, 2004. - 184 с.

20. Приказ Следственного комитета РФ от 15.01. 2011 № 2 «Об организации предварительного расследования в Следственном комитете Российской Федерации». - Доступ из справ.-правовой системы «КонсультантПлюс».

\section{REFERENCES}

1. Akimchev A. A. Problems of Implementation of the Principle of Inviolability of the Home in Criminal Proceedings. Problems of the Theory and Practice of the Criminal Process: History and Modernity. Voronezh, 2006, pp. 355-359. (in Russian).

2. Appeal Decision of the Krasnodar Regional Court of 15.05.2014 № 22-2471/14 in Criminal Case № 22K-2471/2014. Base of Court Decisions "Judicial and normative acts”. URL: http://sudact.ru/regular/ doc/ bFyMNfchT3Zd. (in Russian).

3. Babich A.V. Procedural Independence and Independence of the Investigator as the Basis of His Status in Criminal Proceedings. Cand. jurid. sci. dis. Saratov, 2011. 218 p. (in Russian).

4. Baranova M. A. Does Part 5 of Article 165 of the Criminal Procedure Code of the Russian Federation Guarantee the Constitutional Right to Inviolability of the Home? Constitution of the Russian Federation and development of modern statehood (to the 10th anniversary of the Constitution of the Russian Federation). Sat. on Mater. International. Sci.-Prakt.
Conf. Saratov, October 3-4, 2009. Saratov, 2009, pp. 238240. (in Russian).

5. Baranova M.A., Gasanova S.A., Khalilova R.G. About Some Problems of the Implementation of the Principle of Inviolability of the Home Under Investigation. Actual Problems of Criminal Trial and Criminalistics: Proceedings of the $3^{\text {rd }}$ International. Scientific Practice. Conf. Volgograd. May 25, 2012. Volgograd, 2012, pp. 6-12. (in Russian).

6. Bezrukov. C.C. Evaluation Concepts and Terms in the Criminal Procedure Legislation: Author's Abstract. Cand. jurid. sci. diss. Moscow, 2001. 24 p. (in Russian).

7. Gerasimova L.I. Implementation of the Principle of Inviolability of the Home in the Production of Investigative Actions. Lawyer, 2005, no. 1, pp. 50-52. (in Russian).

8. Zhuk O.D. Features of the Production of Investigative Actions in Criminal Cases on the Organization of the Criminal Community (Article 210 of the Criminal Code). Legislation and Economy, 2003, no. 11, pp. 54-60. (in Russian).

9. Grigorieva N.N. Protection of Housing Rights of Citizens in Court. Legality, 2017, no. 3, pp. 24-26.

10. Kolokolov N.A. Border for the investigator. Ezh-LAWYER, 2008, no. 44, pp. 37-38. (in Russian).

11. Nikiforova Kh.P. On the Issue of Judicial Control of the Legality and Validity of investigative actions that limit the constitutional rights and freedoms of the individual. Vestnik $O G U, 2015$, no. 3 (178), pp. 120-125. (in Russian).

12. Definition of the Constitutional Court of the Russian Federation of 10.03.2005 № 70-O “About Refusal in Acceptance to Consideration of the Complaint of the Citizen Dementieva Aida Borisovna on Violation of Her Constitutional Rights by Part of the Fifth Article 165 of the Code of Criminal Procedure of the Russian Federation". NW of the Russian Federation, 2005, no. 20, art. 1917. (in Russian).

13. Osipov A.B. Normative Model of Exceptional Cases in Which the Production of Investigative Actions does not Tolerate Delay. News Altsu, 2012, no. 2 (74), pp. 124-128. (in Russian).

14. The Resolution of Plenum of the Supreme Court of 01.06.2017 № 19 "On the Practice of Consideration by the Courts of Applications for Investigative Actions Related to the Restriction of Constitutional Rights of Citizens (Article 165 of the Code ofCriminal Procedure). Russian Newspaper, 2017, 09 June. (in Russian).

15. Soloviev A. Ensuring the Validity of the Inspection of the Home, Search and Seizure in the Home in Exceptional Cases, Urgent. Criminal Law, 2004, no. 4, pp. 103-104. (in Russian).

16. Petrukhin I.L., ed. Criminal Procedure Law of the Russian Federation: Textbook. Moscow, Prospect Publ., 2007. 688 p. (in Russian). 
17. Fomichev P.V. Procedural Grounds for Investigative Actions in the Russian Criminal Proceedings. Cand. jurid. sci. diss. Saratov, 2016.234 p. (in Russian).

18. Sabarin B.B. Observance of the Principle of Inviolability of the Home in the Production of Investigative Actions. Bulletin of St. Petersburg University, 2012, no. 3, pp. 80-82. (in Russian).
19. Shaffer C.A. Investigative Actions. Grounds, Procedural Order and Evidentiary Value. Samara, 2004. 184 p. (in Russian).

20. Order of the Investigative Committee of the Russian Federation Dated 15.01.2011 no. 2 "On Organizing a Preliminary Investigation in the Investigative Committee of the Russian Federation". Access from Reference Legal System 'KonsultantPlyus'. (in Russian).

\section{Information about the Author}

Nina S. Manova, Doctor of Sciences (Jurisprudence), Professor, Head of the Department of Criminal Procedure, Saratov State Academy of Law, Chernyshevskogo St., 104, 410056 Saratov, Russian Federation, n.manova@mail.ru, https://orcid.org/0000-0002-2755-2070

\section{Информация об авторе}

Нина Сергеевна Манова, доктор юридических наук, профессор, заведующая кафедрой уголовного процесса, Саратовская государственная академия права, ул. Чернышевского, 104, 410056 г. Саратов, Российская Федерация, n.manova@mail.ru, https://orcid.org/0000-0002-2755-2070 